\title{
Interaction of Microglia and Astrocytes in the Neurovascular Unit
}

\author{
Li-rong Liu ${ }^{1,2+}$, Jia-chen Liu ${ }^{3+}$, Jin-shuang Bao ${ }^{1}$, Qin-qin Bai ${ }^{1}$ and Gai-qing Wang ${ }^{1,4 *}$ \\ ${ }^{1}$ Shanxi Medical University, Taiyuan, China, ${ }^{2}$ People's Hospital of Yaodu District, Linfen, China, ${ }^{3}$ Xiangya Medical College, \\ Central South University, Changsha, China, ${ }^{4}$ SanYa Central Hospital, The Third People's Hospital of HaiNan Province, SanYa, \\ China
}

\section{OPEN ACCESS}

Edited by:

Jorge Matias-Guiu,

Complutense University of

Madrid, Spain

Reviewed by:

Clara Ballerini,

University of Florence, Italy

Souvarish Sarkar

Harvard Medical School,

United States

*Correspondence:

Gai-qing Wang

wanggq08@126.com;

wanggq08@163.com

tThese authors have contributed equally to this work

Specialty section:

This article was submitted to

Multiple Sclerosis and

Neuroimmunology,

a section of the journal

Frontiers in Immunology

Received: 26 February 2020 Accepted: 28 April 2020

Published: 08 July 2020

Citation:

Liu L, Liu J, Bao J, Bai Q and Wang G (2020) Interaction of Microglia and Astrocytes in the Neurovascular Unit.

Front. Immunol. 11:1024.

doi: 10.3389/fimmu.2020.01024
The interaction between microglia and astrocytes significantly influences neuroinflammation. Microglia/astrocytes, part of the neurovascular unit (NVU), are activated by various brain insults. The local extracellular and intracellular signals determine their characteristics and switch of phenotypes. Microglia and astrocytes are activated into two polarization states: the pro-inflammatory phenotype (M1 and A1) and the anti-inflammatory phenotype (M2 and A2). During neuroinflammation, induced by stroke or lipopolysaccharides, microglia are more sensitive to pathogens, or damage; they are thus initially activated into the $\mathrm{M} 1$ phenotype and produce common inflammatory signals such as IL-1 and TNF- $\alpha$ to trigger reactive astrocytes into the A1 phenotype. These inflammatory signals can be amplified not only by the self-feedback loop of microglial activation but also by the unique anatomy structure of astrocytes. As the pathology further progresses, resulting in local environmental changes, M1-like microglia switch to the M2 phenotype, and M2 crosstalk with A2. While astrocytes communicate simultaneously with neurons and blood vessels to maintain the function of neurons and the blood-brain barrier (BBB), their subtle changes may be identified and responded by astrocytes, and possibly transferred to microglia. Although both microglia and astrocytes have different functional characteristics, they can achieve immune "optimization" through their mutual communication and cooperation in the NVU and build a cascaded immune network of amplification.

Keywords: microglia, astrocyte, neuroinflammation, stroke, LPS, NVU

\section{INTRODUCTION}

Neuroinflammation often runs through the entire process of pathological development. There is a dynamic change over time with the regulation of pro and anti-inflammatory signals $(1,2)$. Microglia/astrocytes, part of the neurovascular unit (NVU), are activated by various brain insults. The local extracellular and intracellular signals determine their characteristics and switch of phenotypes. Generally, microglia and astrocytes are activated into two states: the pro-inflammatory phenotype (M1/A1) and the anti-inflammatory phenotype (M2/A2), corresponding to either the destructive or reparative functions in the NVU, respectively (3-5). The activated microglia and astrocytes have dynamic phenotypic changes (6-9).

The crosstalk between microglia and astrocytes occurs through a variety of molecule signals such as adenosine triphosphate (ATP), cytokines, etc. (10). Liddelow et al. (9) showed that reactive astrocytes (A1) can be induced by the cytokines secreted from activated microglia (M1), which are induced by lipopolysaccharides (LPS) in vitro and in vivo (11). Microglia appear to be more sensitive to pathogens or damage, which stimulate them and promote secretion of "molecular signals" to 
trigger reactive astrocytes. Neuroinflammation, such as in stroke, may exhibit a similar mechanism and interaction between microglia, and astrocytes may share the common molecular language in various diseases. It has been previously shown that neuroinflammation between the microglia and astrocytes has a cascade of amplification (12-14), but its mechanism needs further elucidation. As the pathology progresses, thus causing environmental changes, it promotes the switch from M1 to M2, which is also closely associated with A2. While astrocytes, an essential component of the NVU, communicate simultaneously with both neurons and blood vessels as versatile cells to maintain the function of neurons and the blood-brain barrier (BBB), there seems to be a difference in the communication of astrocytes from microglia. This review is concerned with the origin, anatomy, and physiological function of microglia and astrocytes, particularly their communication and cooperation in pathological conditions. The activated microglia and astrocytes may achieve immune "optimization" through their interaction in the NVU.

\section{MICROGLIA AND ASTROCYTES IN THE NVU}

The NVU, a structural and functional unit, is composed of microglia, neurons, the $\mathrm{BBB}$, and the extracellular matrix (15). Its primary function is to meet the brain's dynamic metabolic needs by regulating the cerebral blood flow (CBF) in response to physiological or pathological stimuli in the CNS $(16,17)$. The BBB consists of vascular endothelial cells (ECs), tight junctions, and basement membranes, pericytes, or smooth muscle cells, and astrocytes. It separates parenchyma of the central nervous system (CNS) from blood, and it thus maintains a stable micro-environmental homeostasis of CNS $(18,19)$. The $\mathrm{BBB}$ maintains the low permeability through the tight-junction between sendothelial cells with membrane-bound transporters, and perivascular cells, such as pericytes, astrocytes, and the extracellular matrix, also contribute to this $(17,20)$. Astrocytes promote the maintenance of the $\mathrm{BBB}$ via sonic hedgehog and b-catenin, which strengthen the tight junction and integrity (21). Meanwhile, reactive astrocytes disrupt the local BBB by the release of vascular endothelial growth factor (VEGF), increase permeability, and allow entry of peripheral immune cells $(22,23)$.

Astrocytes are considered an indispensable element of the NVU or extended BBB. In the context of the NVU,

\footnotetext{
Abbreviations: NVU, Neurovascular unit; LPS, Lipopolysaccharides; CNS, Central nervous system; ATP, Adenosine triphosphate; BBB, Blood-brain barrier; ECs, Endothelial cells; VEGF, Vascular endothelial growth factor; MMP-9, Matrix metalloproteinase-9; CX, Connexin; CBF, Cerebral blood flow; ROS, Reactive oxygen species; TNF, Tumor necrosis factor; IL- $1 \beta$, Interleukin 1 beta; IL- $1 \alpha$, Interleukin-1 alpha; iNOS, Inducible nitric oxide synthase; TGF $\beta$, Transform growth factor beta; CLCF1, Cardiotrophin-like cytokine factor 1; LIF, Hypoxia induce factor; C1q, Complement component subunit 1q; SAH, Subarachnoid hemorrhage; PAMP, Pathogens associated molecular pattern; DAMP, Damage associated molecular pattern; HMGB1, High-mobility group protein box-1; COX, Cyclooxygenase; Pb, Plumbum; GFAP, Glial fifibrillary acidic protein; AD, Alzheimer's disease; NO, Nitric oxide; MCAO, Middle cerebral artery occlusion.
}

astrocytes are located in the center between neurons and ECs. The strategic position of astrocytes enable them to regulate $\mathrm{CBF}$ to adapt to dynamic changes in neuronal metabolism and synaptic activity $(18,24)$. Astrocytes cooriginate with neurons and oligodendrocytes and are produced in the final stages of neurogenesis $(25,26)$. They are the most abundant and heterogeneous glia cell type, tiling throughout the brain in a non-overlapping manner in the CNS (27).

Astrocytes are closely associated with neurons and blood vessels as versatile cells $(28,29)$ and communicate with neuronal pre- and post-synaptic terminals to help modulate synaptic transmission by the release of glutamate, D-serine, and ATP. It has been reported that one astrocyte can supervise over 100,000 synapses (30-33). Astrocytes can be extensively coupled into syncytial structures of up to 100 units by gap junctions, composed of connexin (CX) proteins such as CX-43 and CX-30 subtypes, allowing for the rapid facilitation of longrange signaling through calcium waves (34-37). Astrocytes extend end-feet processes to cover the surface of cerebral blood vessels with a ratio of $\sim 99 \%$ to modulate $\mathrm{CBF}$ or the $\mathrm{BBB}$ (24). Furthermore, the end-feet with high levels of aquaporin4 water channel proteins promote perivascular clearance by the newly characterized "glymphatic system" (CNS waste clearance system) $(38,39)$.

Astrocytes were, in the past, considered simply as a supportive or "glue-"like function in the CNS; now, their essential functions are increasingly being elucidated (28). Besides the above mentioned effects of "glymphatic system" (39, 40), astrocytes also have neurotrophic support, promote formation, and maintenance of synaptic activity, and transmission, regulate $\mathrm{CBF}$, and determine some functions, and properties of the BBB, or NVU (27). In physiological conditions, astrocytes restrict the entry of peripheral immune cells passing through the BBB (41). While in pathological conditions, astrocytes participate in innate immune reactions (42) and the adaptive immune responses by their strategic position $(43,44)$.

Microglia, an important partner of the NVU, are the primary immune cells and account for $\sim 5-15 \%$ of all cells in the human brain $(45,46)$. Early in development, microglia derive from the yolk sac, and seed in the brain as the first glial cells, and they develop concurrently with neurons into highly plastic cells with mobility (47-49). Under physiological or pathological conditions, microglia continuously survey their surrounding environment and always firstly respond to any insult in the CNS (50-52).

There is a local network of immune cells via communication and collaboration in the CNS against pathogenic insults, injury, or stress (44). Microglia, scattered throughout the brain, wander more observantly and detect modifications of their environment as sentinels $(42,53)$. Whether as the first glial cells seeded in the brain early in embryonic development or as the first to respond to insults in CNS, microglia are always the "pioneers" in the NVU. On the other hand, astrocytes with a more dominant quantity may be "reserve forces" and amplify the neuroinflammation, owing to syncytium of the structure and function and strategic position to mobilize peripheral immunity (54). 


\section{ASSOCIATION OF MICROGLIA, ASTROCYTES, AND NEUROINFLAMMATION}

Neuroinflammation is constantly present at every different pathological state in CNS diseases. Neuroinflammation is induced when the NVU responds to specific stimuli involved in the activation of microglia and astrocytes, breakdown of the BBB, infiltration of peripheral leukocytes, and inflammation factors, etc. (55). Activated microglia and reactive astrocytes play a crucial role in neuroinflammation. The dynamic phenotypic changes of microglia and astrocytes determine their detrimental or beneficial character at particular stages $(7,9)$. Microglia and astrocytes in NVU is illustrated in Figure $\mathbf{1 .}$

\section{Microglia}

Microglia, the first activated innate immune cells, can be activated within minutes of tissue damage (56). Activated microglia, with changes from the ramified morphology into an amoeboid shape, upregulate the secretion of numerous inflammation factors, and microglial phagocytosis (57). The local extracellular and intracellular signals determine their characteristics and switch of phenotypes, which range from "M1-like" phenotypes characterized by increase of inflammatory mediators, such as tumor necrosis factor (TNF), interleukin 1 beta (IL-1 $\beta$ ), and reactive oxygen species (ROS) (58), to "M2-like" phenotypes characterized by upregulation of anti-inflammatory mediators, such as Interleukin IL-10, transforming growth factor beta (TGF $\beta$ ), and glucocorticoids (59). The M1-like phenotype is considered to be destructive to NVU (60), while the M2- like phenotype is interpreted to be nerve repair cells in CNS diseases (61). Moreover, microglia display intermediate phenotypes with diverse combination of polarization markers ranging from M1 to M2, representing the crossroads of diverse pro- and antiinflammatory (62-64). Although the supposed dichotomy of M1/M2 phenotypes hardly reflect a wide range of microglial phenotypes, this facilitates understanding of the activated state of microglia in various CNS disorders (3).

\section{Astrocytes}

Astrocytes are another type of glial cells that actively participate in regulation of neuroinflammation, depending on the timing and context (65). Following diverse brain injuries, astrocytes undergo a significant transformation called "reactive astrocytosis," whereby they upregulate many genes, increase the size of cytoskeleton, process extension, increase expression and immunoreactivity of glial fibrillary acidic protein (GFAP), and form a glial scar $(5,66,67)$. Reactive astrocytes were purified and genetically analyzed in mice about neuroinflammation induced by systemic injection of LPS or cerebral ischemia induced by middle cerebral artery occlusion (MCAO). Neuroinflammation and ischemia induced two different types of reactive astrocytes, which correspond to "A1" pro-inflammatory and "A2" antiinflammatory, respectively. This nomenclature is similar to the "M1" and "M2" of microglia (9). Different polarizations of astrocytes are marked by different biochemical and functional characteristics (68-70). A1 reactive astrocytes elevate levels of

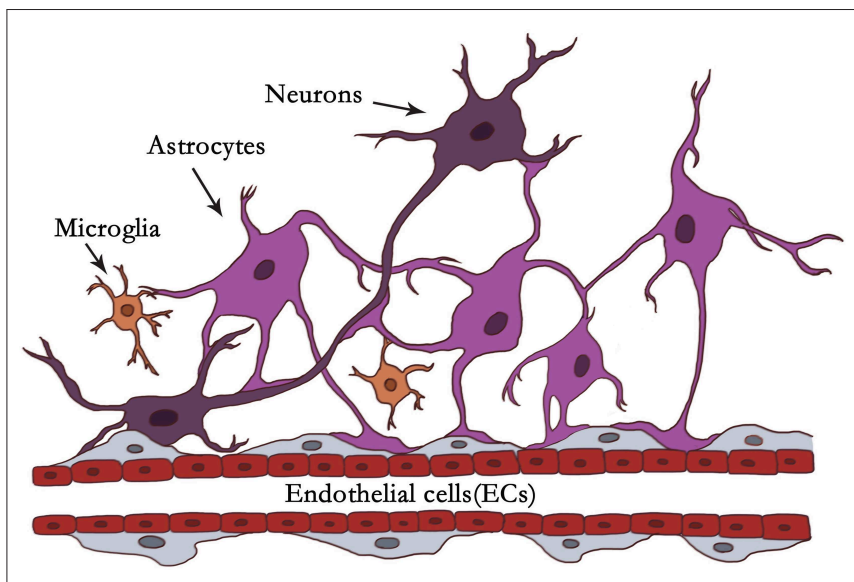

FIGURE 1 | Illustration of microglia and astrocytes in NVU. In the context of the NVU, astrocytes are located in the center between neurons and endothelial cells (ECs). Astrocytes are closely associated with neurons and blood vessels as versatile cells. Astrocytes communicate with neuronal pre- and postsynaptic terminals to help modulate synaptic transmission. It has been reported that one astrocyte can supervise over 100,000 synapses. Astrocytes extend end-feet processes to cover the surface of cerebral blood vessels with a ratio of $\sim 99 \%$ to modulate $\mathrm{CBF}$ or the BBB. Astrocytes can be organized into syncytial structures of up to 100 units by gap junctions to facilitate long-range signaling. Microglia account for about $5-15 \%$ of all cells in the human brain. Under physiological or pathological conditions, they scan their environment through scavenging functions. Microglia firstly react to brain insults like "pioneers," monitoring and transmitting "danger." Astrocytes with dominant quantity may be "reserve forces" and amplify the neuroinflammation, owing to their syncytium of the structure, and function, and strategic position to mobilize peripheral immunity.

many genes of the classic complement cascade, such as $\mathrm{C} 1 \mathrm{r}$, $\mathrm{C} 1 \mathrm{~s}$, C3, and C4, which are harmful for the NVU. Meanwhile, A2 reactive astrocytes upregulate beneficial inflammatory factors, such as CLCF1 (cardiotrophin-like cytokine factor 1), LIF (hypoxia induce factor), IL-6, IL-10, and thrombospondins, to promote the NVU remodeling $(5,9)$. Reactive astrocytosis also represents a spectrum of alterations reflecting the specific insults in the CNS $(9,54)$.

The association of microglia, astrocytes, and neuroinflammation is illustrated in Figure 2.

\section{INTERACTION OF MICROGLIA AND ASTROCYTES IN THE NVU \\ The Common Molecular Signals of Interaction}

Reactive astrocytes are induced by LPS-activated microglia (11, 56, 71). Liddelow et al. (9) showed that reactive astrocytes (A1) can be induced by cytokines, such as interleukin-1 alpha (IL-1 $\alpha$ ), TNF- $\alpha$, and the complement component subunit 1q (C1q), which secreted by activated microglia (M1) both in vitro and in vivo. (11). Microglia appear to be more sensitive to pathogens; they activate and secrete "molecular signals" to trigger reactive astrocytes. Interaction between activated microglia and astrocytes plays a crucial role in the process of 


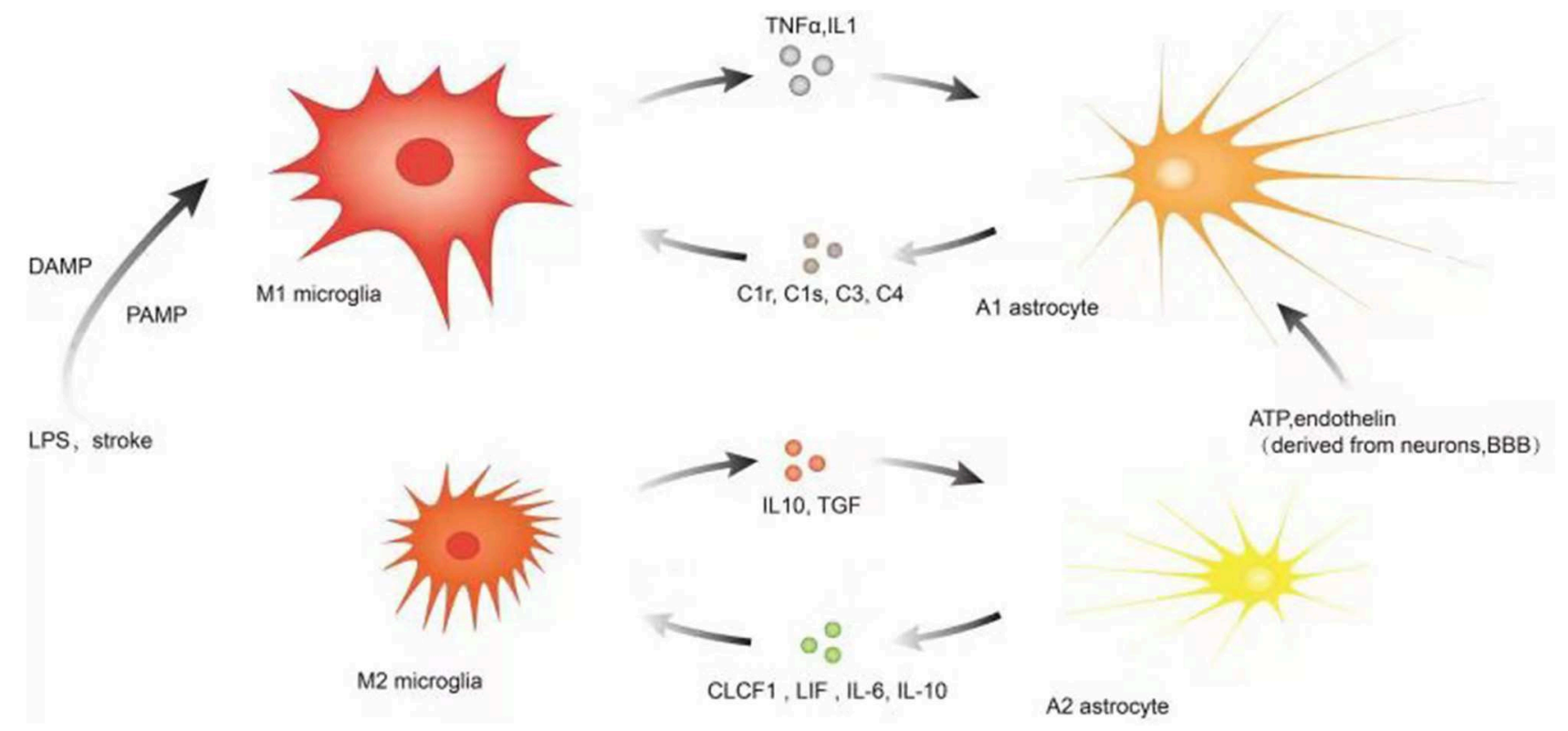

FIGURE 2 | Illustration of microglia, astrocytes, and neuroinflammation. Microglia are more sensitive to pathogens/damage such as LPS or stroke, firstly activated into M1-like phenotypes via PAMP/DAMP and promote the secretion of inflammatory factors such as TNF-a, IL-1, etc. to trigger reactive astrocyte (A1). As the insult limited and the NVU is remodeling, the local environmental factors change and determine M2-like phenotype to upregulate microglial phagocytosis and secretion of IL10, TGF, etc. Simultaneously, the local environmental factors may promote the switch to A2. Astrocytes communicate simultaneously with both neurons and blood vessels as versatile cells to maintain the function of neurons and the blood-brain barrier, and their subtle changes may be captured and responded by astrocytes and even transferred to microglia. A variety of molecular signals such as ATP, endothelin, etc. trigger reactive astrocytes (A1) and A1 upregulates many genes of the classic complement cascade such as $\mathrm{C} 1 \mathrm{r}, \mathrm{C} 1 \mathrm{~s}, \mathrm{C} 3$, and $\mathrm{C} 4$, which communicate with microglia via some corresponding complement receptors; $\mathrm{A} 2$ elevates the levels of neurotrophic factors and cytokines such as CLCF1, LIF, IL-6, IL-10, and thrombospondins to promote neuronal survival and repair; the local environmental factors promote the switch to M2-like phenotype.

neuroinflammation. Neuroinflammation of diverse CNS diseases such as stroke may share the common "molecular signals" to trigger astrocytes reaction, and these inflammation signals may be amplified (72).

The activation of microglia occurs early in the timeline of neuroinflammation following stroke besides LPS-induced inflammation. Microglial activation within the perihematomal region, by immunofluorescence staining, was seen within $1 \mathrm{~h}$ of intracerebral hemorrhage $(\mathrm{ICH})$ in a model of $\mathrm{ICH}(73,74)$. In a clinical study of perihematomal brain tissue, TNF and IL-1 $\beta$ levels increased within 1 day of $\operatorname{ICH}(75,76)$. After collagenaseinduced or autologous blood-induced ICH, IL-1 $\beta$, TNF, IL-6 $(77,78)$, and inducible nitric oxide synthase (iNOS) (25), mRNA levels were generally upregulated in the acute phase, starting to rise in the first $3 \mathrm{~h}$ after ICH and peaking at 3 days (79, $80)$. Changes in the protein levels corresponded to the timeline $(25,80,81)$. Similarly, in the acute phase of ischemic stroke, microglia were activated first and invaded the peri-infarct and infarct core to orchestrate the post-stroke neuroinflammatory response and communicated with astrocytes through soluble and membrane-bound signaling molecules (82-84), including the cytokines IL-1 $\beta$, TNF, and IL-1 receptor antagonist (IL$1 \mathrm{Ra})(82,83,85)$. These studies imply that microglia in stroke are more sensitive to pathogens/damage; which are activated and produce then produce the common "molecular signals," such as IL- 1 and TNF, to trigger reactive astrocytes $(11,86)$.
Meanwhile, another study showed highly enriched astrocyte cultures produced only a very few inflammatory factors, such as TNF- $\alpha$, reactive oxygen species (ROS), and nitric oxide (NO), in response to LPS stimulation. Astrocytes seem to be sluggish in response to pathogens stimulation and fail to be completely activated in the absence of microglia (87).

TNF- $\alpha$ is a multi-effect cytokine mostly released from microglia/macrophages (88) and neutrophils (89). The IL1 cytokine family has a large number of members, and the most important are IL- $1 \alpha$, IL-1 $\beta$, and the natural receptor antagonist IL-Ra (90). Further, IL-1 $\beta$ is mainly derived from microglia/macrophages (91). Both TNF- $\alpha$ and IL-1 primarily produced by microglia/macrophages are overexpressed within the first $2 \mathrm{~h}$ after experimental $\mathrm{ICH}$ (92-94) and as early as $24 \mathrm{~h}$ after ischemic stroke in mice (82).

Microglia are firstly activated via TLR4 by the pathogens or damage and release the inflammation mediators TNF- $\alpha$ (95). Sansing et al. (96) showed that activated microglia express high levels of TLR4, which result in neuroinflammation after ICH. Meanwhile, astrocytes respond through activation of TLR2, TLR3, and TLR4, almost depending on the presence of microglia (97). In the case of TLR4 activation in response to LPS, microglia directly trigger or promote astrocytic responses by upregulating the expression levels of soluble mediators. The results indicate that microglia play a critical role in astrocytic activation via 


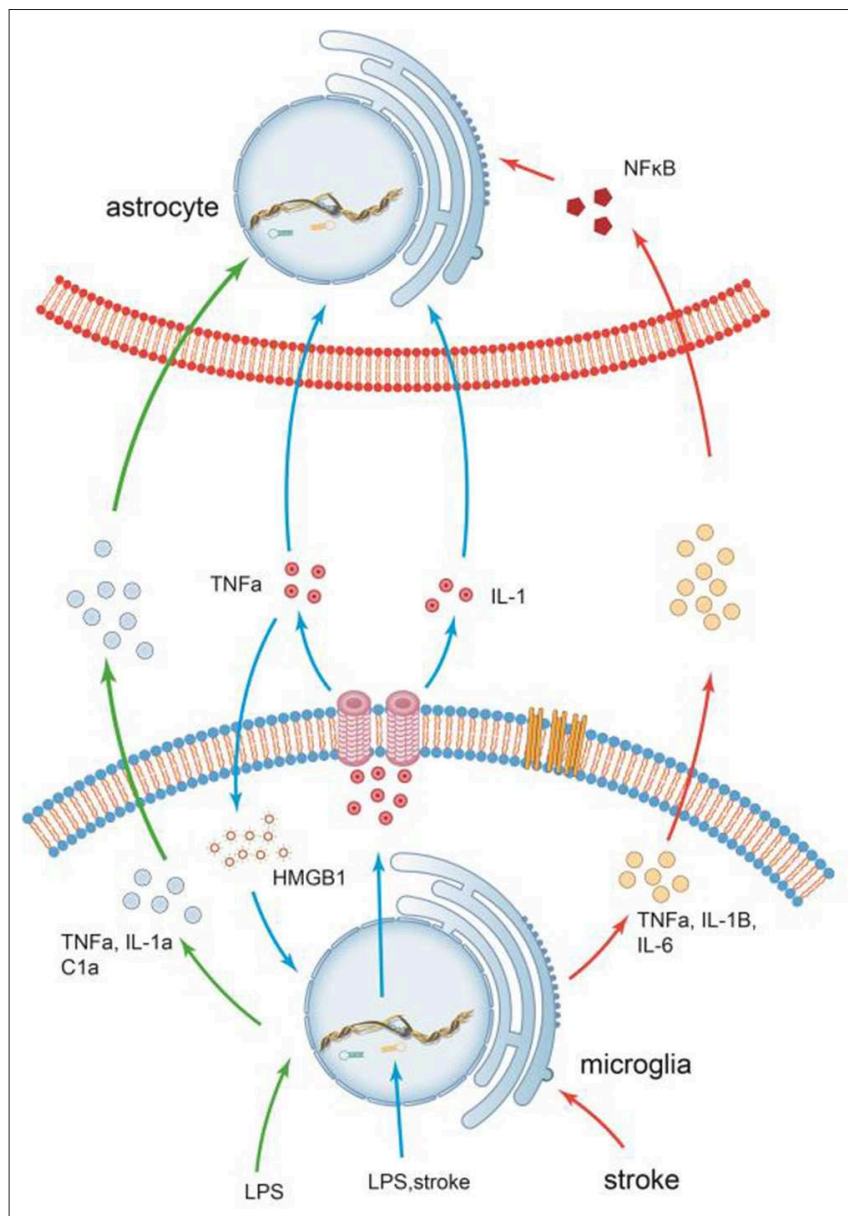

FIGURE 3 | The communications of microglia and astrocytes. Pathogens/damage trigger M1-like microglia via TLR4. During the neuroinflammation induced by LPS or stroke, Microglia are more sensitive to pathogens/damage, firstly activated, and secrete the common "molecular signals," such as IL-1 and TNF-a, to trigger reactive astrocytes. Different types of insults release different combinations of these molecules, which in turn trigger different responses. It has been demonstrated that inflammation factors induced by LPS, such as TNF- $\alpha, \mathrm{IL}-1 \mathrm{a}$, and C1a, can trigger reactive astrocytes. In stroke, however, the inflammatory factors secreted by activated microglia(M1), such as TNF- $\alpha, I L-1 \beta$, and IL-6, are significantly elevated. Recombinant human HMGB1 (rhHMGB1) can trigger microglial activation via the TLR4 and increase production of TNF- $\alpha$, which in turn stimulates microglia to release large amounts of HMGB1 to active more microglia. There seems to be self-feedback loop in the activation process of microglia.

TLR4 in response to insults, injury, or inflammation in CNS disorders $(14,97)$.

It is observed that human astrocytes are highly sensitive to IL-1 $\beta$ but unresponsive to LPS stimulation, and reactive astrogliosis is also induced by IL- $1 \beta$ alone (98). Within $24 \mathrm{~h}$ of IL$1 \beta$ induction, large numbers of reactive astrocytes are observed, and elevate the matrixmetalloprotease (MMP)-9 expression (98100). Although astrocytes produce certain pro-inflammatory factors, microglia are the main source of cytokines (101). Primary mediators, such as TNF, IL-1 $\beta$, and IFN $\gamma$, promote the produce of secondary mediators, such as MMP, nitric oxide(NO), and arachidonic acid (72).

These evidences suggest that, in the process of neuroinflammation induced by stroke or LPS, microglia are more sensitive to pathogens/damage and activated via PAMP/DAMP and release the common "molecular signals" or primary mediators, such as IL- 1 and TNF- $\alpha$, to trigger reactive astrocytes, while astrocytes are unresponsive to pathogens/damage in the absence of microglial cells.

\section{HMGB1}

High-mobility group protein box-1(HMGB1), a highly conserved non-histone DNA-binding protein, is involved in pro-inflammatory cytokine gene transcription in diverse inflammatory diseases $(56,102-104)$. In a rabbit subarachnoid hemorrhage (SAH) model, the Murakami group found that the HMGB1 protein are located in microglia and macrophages with a ratio $>90 \%$ (105). In a collagenase-induced mode of $\mathrm{ICH}$ in rats, the release of HMGB1 into the cytoplasm in the brain was detected within $1 \mathrm{~h}$, and express levels of HMG1 protein was substantially elevated at $24 \mathrm{~h}$ after ICH (106-108). These suggest that HMGB1 also primarily arise from microglia/macrophages and seem to be produced concurrently with cytokines such as IL1 and TNF- $\alpha$.

In vitro, microglia stimulated by TNF- $\alpha$ release large amounts of HMGB1 (109), and recombinant human HMGB1 (rhHMGB1) can activate microglia, increase NF- $\mathrm{B}$ activity, and promote inflammation factors including TNF- $\alpha$, IL- $1 \beta$, cyclooxygenase (COX) -2 , and NO (110). However, these effects disappeared in TLR4-/- microglia treated with rhHMGB1 (110). These observations indicate that not only pathogens/damage but also HMGB1 can ignite microglial activation via TLR4 and promotes the produce of $\mathrm{TNF}-\alpha$, which in turn stimulates microglia to release large amounts of HMGB1 to active more microglia. There seems to be self-feedback loop in the process of microglial activation.

\section{Signal Can be Amplified}

Molecular languages, such as TNF- $\alpha$ and IL-1 is not only the proinflammatory factors of M1-like phenotypes, but more like "signals" to trigger reactivity astrocytes, and these inflammatory signals may be amplified by the unique physiological structure of astrocytes. A rat model experiment indicated that primary microglia are more sensitive to lead $(\mathrm{Pb})$ exposure; compared to astrocytes, $\mathrm{Pb}$ is more likely to reduce microglial viability, while astrocytes have greater uptake of Pb (111). Similarly, the Kirkley group found that microglia can amplify the inflammatory activation of astrocytes by the release of cytokines and chemokines (12).

ATP and analogs interacts with G protein-coupled P2Y receptors to promote astrocyte proliferation and the growth of long, branched processes (101). It has also been shown that microglial cells quickly released small amounts of ATP, and astrocytes in turn amplified this release, increasing the frequency of excitatory postsynaptic currents through P2Y1 (14). This response can be blocked by inhibitors of connexin channels. In the case of connexin channel inhibitors, microglial movement 
is also significantly impeded (112). These results reveal that microglia as upstream partners ignite the response and astrocytes with the syncytium coupled by connexin channels magnify this.

In conclusion, microglia firstly react like "pioneers" in the NVU, initiate immune cascades, release inflammatory mediators, and form network regulation. Meanwhile, astrocytes with dominant quantity may be "reserve forces" and amplify the neuroinflammation, owing to their syncytium of structure and function. In addition, the amplification of neuroinflammation may be also related to astrocytic strategic position to mobilize peripheral immunity.

\section{Communication Between M2 and A2}

As mentioned above, the M1-like microglia secrete some proinflammatory mediators to induce A1 astrocytes, which amplify the cascaded neuroinflammation. With the process of the insults limited and the NVU remodeling, the local environmental factors change and determine the switch of microglial and astrocytic phenotypes. Activated microglia-Derived Cytokines (TNF- $\alpha$, IL$1 \beta$ and IL-6) induced the switch of astrocyte phenotype after brain trauma (113). The interaction of microglia and astrocytes plays a vital role in the switch of phenotypes. In addition, activated M2-like microglia produce the anti-inflammatory cytokine IL-10, which matches the IL-10 receptor (IL-10R) primarily expressed in A2 astrocytes, and this allows astrocytes to secrete TGF- $\beta$, which reduces microglial activation (114). The communication between M2 and A2 significantly promotes neuronal survival and repair and is even amplified by the unique anatomy structure of astrocytes.

\section{Astrocytic Dialogue to Microglia}

In physiological conditions, astrocytes communicate simultaneously with both neurons and blood vessels as versatile cells to maintain the function of neurons and the blood-brain barrier (27). In pathological conditions, reactive astrogliosis, and astrocytic proliferation become dominant, and the process is triggered by diverse molecular signals, such as cytokines, ATP, endothelin, sonic hedgehog, fibroblast growth factor2 (FGF2), thrombin, and bone morphogenic proteins (BMP) $(27,115)$. The communications among neurons, BBB and microglia/macrophage mostly rely on these molecular signals $(11,13,21,116)$. Early triggers contain nucleotides released from damaged cells and pro-inflammatory cytokines as well as purines/pyrimidines such as ATP and elevated excitotoxic transmission, as ATP is co-released with neurotransmitters (101). In physiological or pathological conditions, astrocytes seem to primarily sense the signals derived from neurons and blood-brain barrier components including microglia in the NVU.

During development, astrocytes can sense subtle changes in neurons to induce the production of $\mathrm{Clq}$ in neuronal synapses, which interacts with the microglial $\mathrm{C} 3 \mathrm{a}$ receptor $(\mathrm{C} 3 \mathrm{aR})$ to prune the neuronal synapses through the classic cascade complement pathway (117). In the context of Alzheimer's disease (AD) pathology, overproduction of $\mathrm{AD}$ promote the release of $\mathrm{C} 3$ from astrocytes, which simultaneously communicate with microglial $\mathrm{C} 3 \mathrm{aR}$ and neuronal $\mathrm{C} 3 \mathrm{aR}$ to dynamically regulate microglial phagocytosis and impair dendritic morphology as well as synaptic function, subsequently deteriorate cognitive function. The damaged neurons in turn trigger more astrocytes and active more microglia. Complement-dependent intercellular crosstalk is critical to promote the pathogenic cycle, and the feedforward loop can be blocked effectively by C3aR inhibition $(118,119)$.

Astrocytes are major sources of many chemokines, such as CCL2, CXCL1, CXCL10, and CXCL12 (120-122), and microglia express some corresponding chemokine receptors, such as CCL2, CXCL12 (123, 124), and so on. This implicates a strong association between microglia and astrocytes.

In summary, astrocytes, one of the important components of the NVU, communicate simultaneously with both neurons and blood vessels as versatile cells to maintain the function of neurons and the blood-brain barrier, whose subtle changes are captured and responded to by astrocytes, and even transferred to microglia. In early mild cognitive impairment, astrocytes may be the primary responsibility for this, but, in moderate or severe cognitive impairment such as $\mathrm{AD}$, amounts of accompanied neurons death or apoptosis may also directly activate microglia, as microglia are more sensitive to pathogens/damage and trigger more reactive astrocytes via inflammatory signals, which can be amplified not only by the self-feedback loop of HMGB1 but also by the unique anatomy structure of astrocytes. Although both microglia and astrocytes own their functional characteristics, they can achieve the immune "optimization" through their mutual communication and cooperation in neuroinflammation.

The communications of microglia and astrocytes is illustrated in Figure 3.

\section{Different Pathogens/Damage and Different Effects}

The inflammatory effects of the central nervous system depend on several parameters, including the types and severity of pathogens/damage, glial cell types, a variety of combinations of signal molecules (including chemokines, cytokines, etc.), and timeline of the response, etc. $(112,125,126)$.

Zamanian et al. showed that reactive astrocytes induced by LPS or ischemic stroke upregulate over 1,000 genes, and genomic profiling has shown that both gene representation and fold induction correspond to individual injuries. Some of the upregulated genes are unique to the LPS subtype (A1) or the middle cerebral artery occlusion (MCAO) subtype (A2). For example, the three genes, including Ptx3, S1Pr3, and tweak, are markers for the MCAO subtype (A2), while H2-D1 and Serping1 are markers for the LPS subtype (A1) of reactive astrocytes. H2-D1 was induced 30 -fold by LPS but only 3-fold by MCAO. Serping1 was induced 6.5-fold after MCAO and 34-fold after LPS (5). These data indicate that different pathogens/damage can induce different phenotypes of astrocytes. This may closely relate to the different interaction between the activated astrocytes and microglia, which contain different combinations of molecule signals. It has been demonstrated that inflammation factors induced by LPS, such as TNF- $\alpha$, IL-1a, and C1al, can trigger reactive astrocytes (11). In stroke, the inflammatory factors secreted by activated microglia (M1), such as TNF- $\alpha$, IL- $1 \beta$, 
and IL-6, are significantly elevated $(77,78,127)$. Furthermore, a recent clinical inflammatory factor test is about the relationship of inflammatory markers and severity of $\mathrm{ICH}$, and this test displayed that high TNF-a is closely associated with the size of edema around the hematoma and increase of early hematoma, leading to poor functional recovery and high mortality (128). These studies imply the different types and severities of insults release different combinations or levels of these molecule signals, which in turn trigger different responses.

Thus, different pathogens/damage correspond to different phenotypes of glia cells. Even the same pathogens/damage with the different levels of stimulation, the activated levels and phenotypic timeline of glia cell are also different. In the pathology of neuroinflammation induced by LPS, the pathogen is stronger, M1/A1 are primary, and it is critical to suppress the proinflammatory or shorten the phase. While sterile inflammation induced by stroke, such as cerebral infarction or hemorrhage, it may be beneficial to moderately attenuate the activation levels and shorten the timeline of M1/A1 or strengthen A2/M2, some studies and experiments have confirmed this (85, 129-131). In degenerative disease, such as $\mathrm{AD}$, it may be beneficial to enhance the A2/M2 for brain repair and functional recovery. While in autoimmune diseases such as multiple sclerosis, autoimmune encephalitis, attenuating M1/A1 in time may be more beneficial (132-139).

\section{SUMMARY AND OUTLOOK}

Neuroinflammation is dynamic with the regulation of pro and anti-inflammatory signals. The activation and interaction of glial cells play a crucial role at different stages of pathology in CNS disorders. Microglia are more sensitive to pathogens or damage, firstly activated (M1) like "pioneers," monitoring and transmitting "danger" via the common molecule signals to trigger reactive astrocytes (A1). Astrocytes with dominant quantity may be "reserve forces" and amplify the neuroinflammation, owing to their syncytium of the structure, and function, and

\section{REFERENCES}

1. DiSabato DJ, Quan N, Godbout JP. Neuroinflammation: the devil is in the details. J Neurochem. (2016) 139:136-53. doi: 10.1111/jnc.13607

2. Anrather J, Iadecola C. Inflammation and stroke: an overview. Neurotherapeutics. (2016) 13:661-70. doi: 10.1007/s13311-016-0483-X

3. Hu X, Leak RK, Shi Y, Suenaga J, Gao Y, Zheng P, et al. Microglial and macrophage polarization-new prospects for brain repair. Nat Rev Neurol. (2015) 11:56-64. doi: 10.1038/nrneurol.2014.207

4. Xiong XY, Liu L, Yang QW. Functions and mechanisms of microglia/macrophages in neuroinflammation and neurogenesis after stroke. Prog Neurobiol. (2016) 142:23-44. doi: 10.1016/j.pneurobio.2016. 05.001

5. Zamanian JL, Xu L, Foo LC, Nouri N, Zhou L, Giffard RG, et al. Genomic analysis of reactive astrogliosis. J Neurosci. (2012) 32:6391-410. doi: 10.1523/JNEUROSCI.6221-11.2012

6. Jha MK, Lee WH, Suk K. Functional polarization of neuroglia: implications in neuroinflammation and neurological disorders. Biochem Pharmacol. (2016) 103:1-16. doi: 10.1016/j.bcp.2015. 11.003 strategic position to mobilize peripheral immunity. Although inflammation signals between microglia and astrocytes may share the common inflammatory signals, such as IL- 1 and TNF- $\alpha$, different pathogens and pathological conditions may correspond to different inflammatory signals (TNF- $\alpha$, IL-1 $\beta$, and IL-6 are significantly elevated in stroke, while TNF- $\alpha$, IL-1a, and C1a induced by LPS can trigger markedly reactive astrocytes), and different strategies may be required. As the pathology further progresses, the communication between M2 and A2 significantly promote neuronal survival and repair. In addition, astrocytes, as one of the essential components of the neurovascular unit (NVU), communicate simultaneously with both neurons and blood vessels as versatile cells to maintain the function of neurons and the BBB; their subtle changes are identified and responded by astrocytes and even transferred to microglia. Activated microglia and reactive astrocyte may achieve the immune "optimization" through mutual communication and cooperation in neuroinflammation. Inflammation signals between microglia and astrocytes can be amplified not only by the self-feedback loop of microglial activation but also by the unique anatomy structure of astrocytes in the immune network (140-148). With advancements in technology, the interaction of microglia and astrocytes may be an effective and accurate therapeutic target in the future.

\section{AUTHOR CONTRIBUTIONS}

GW revised the work critically for intellectual content and contributed equally to the work. JL contributed to the drawing. JB and QB assisted drawing. All authors contributed to the article and approved the submitted version.

\section{FUNDING}

Financial support was from the National Natural Science Foundation of China (Project no. 81771294).
7. Lan X, Han X, Li Q, Yang QW, Wang J. Modulators of microglial activation and polarization after intracerebral haemorrhage. Nat Rev Neurol. (2017) 13:420-33. doi: 10.1038/nrneurol.2017.69

8. Shi Y, Yamada K, Liddelow SA, Smith ST, Zhao L, Luo W, et al. ApoE4 markedly exacerbates tau-mediated neurodegeneration in a mouse model of tauopathy. Nature. (2017) 549:523-7. doi: 10.1038/nature24016

9. Liddelow SA, Barres BA. Reactive astrocytes: production, function, and therapeutic potential. Immunity. (2017) 46:95767. doi: 10.1016/j.immuni.2017.06.006

10. Jha MK, Jo M, Kim JH, Suk K. Microglia-astrocyte crosstalk: an intimate molecular conversation. Neuroscientist. (2019) 25:227-40. doi: 10.1177/1073858418783959

11. Liddelow SA, Guttenplan KA, Clarke LE, Bennett FC, Bohlen CJ, Schirmer $\mathrm{L}$, et al. Neurotoxic reactive astrocytes are induced by activated microglia. Nature. (2017) 541:481-7. doi: 10.1038/nature21029

12. Kirkley KS, Popichak KA, Afzali MF, Legare ME, Tjalkens RB. Microglia amplify inflammatory activation of astrocytes in manganese neurotoxicity. J Neuroinflammation. (2017) 14:99. doi: 10.1186/s12974-017-0871-0

13. Litwin M, Radwanska A, Paprocka M, Kieda C, Dobosz T, Witkiewicz $\mathrm{W}$, et al. The role of FGF2 in migration and tubulogenesis of endothelial 
progenitor cells in relation to pro-angiogenic growth factor production. $\mathrm{Mol}$ Cell Biochem. (2015) 410:131-42. doi: 10.1007/s11010-015-2545-5

14. Pascual O, Ben Achour S, Rostaing P, Triller A, Bessis A. Microglia activation triggers astrocyte-mediated modulation of excitatory neurotransmission. Proc Natl Acad Sci USA. (2012) 109:E197-205. doi: 10.1073/pnas.1111098109

15. del Zoppo GJ. The neurovascular unit in the setting of stroke. J Intern Med. (2010) 267:156-71. doi: 10.1111/j.1365-2796.2009.02199.x

16. Muoio V, Persson PB, Sendeski MM. The neurovascular unit-concept review. Acta Physiologica. (2014) 210:790-8. doi: 10.1111/apha.12250

17. Sa-Pereira I, Brites D, Brito MA. Neurovascular unit: a focus on pericytes. Mol Neurobiol. (2012) 45:327-47. doi: 10.1007/s12035-012-8244-2

18. Carmichael ST. Emergent properties of neural repair: elemental biology to therapeutic concepts. Ann Neurol. (2016) 79:895906. doi: 10.1002/ana.24653

19. Obermeier B, Daneman R, Ransohoff RM. Development, maintenance and disruption of the blood-brain barrier. Nat Med. (2013) 19:158496. doi: $10.1038 / \mathrm{nm} .3407$

20. Rajasekaran SA, Beyenbach KW, Rajasekaran AK. Interactions of tight junctions with membrane channels and transporters. Biochim Biophys Acta. (2008) 1778:757-69. doi: 10.1016/j.bbamem.2007.11.007

21. Liebner S, Dijkhuizen RM, Reiss Y, Plate KH, Agalliu D, Constantin G. Functional morphology of the blood-brain barrier in health and disease. Acta Neuropathol. (2018) 135:311-36. doi: 10.1007/s00401-018-1815-1

22. Argaw AT, Asp L, Zhang J, Navrazhina K, Pham T, Mariani $\mathrm{JN}$, et al. Astrocyte-derived VEGF-A drives blood-brain barrier disruption in CNS inflammatory disease. J Clin Invest. (2012) 122:2454-68. doi: 10.1172/jci60842

23. Argaw AT, Gurfein BT, Zhang Y, Zameer A, John GR. VEGF-mediated disruption of endothelial CLN-5 promotes blood-brain barrier breakdown. Proc Natl Acad Sci USA. (2009) 106:1977-82. doi: 10.1073/pnas.08086 98106

24. Filosa JA, Morrison HW, Iddings JA, Du W, Kim KJ. Beyond neurovascular coupling, role of astrocytes in the regulation of vascular tone. Neuroscience. (2016) 323:96-109. doi: 10.1016/j.neuroscience.2015.03.064

25. Yang S, Chen Y, Deng X, Jiang W, Li B, Fu Z, et al. Hemoglobin-induced nitric oxide synthase overexpression and nitric oxide production contribute to blood-brain barrier disruption in the rat. J Mol Neurosci. (2013) 51:35263. doi: 10.1007/s12031-013-9990-y

26. Skoff RP. Gliogenesis in rat optic nerve: astrocytes are generated in a single wave before oligodendrocytes. Dev. biol. (1990) 139:149-68. doi: 10.1016/0012-1606(90)90285-q

27. Sofroniew MV, Vinters HV. Astrocytes: biology and pathology. Acta Neuropathol. (2010) 119:7-35. doi: 10.1007/s00401-009-0619-8

28. Santello M, Cali C, Bezzi P. Gliotransmission and the tripartite synapse. Adv Exp Med Biol. (2012) 970:307-31. doi: 10.1007/978-3-7091-0932-8_14

29. Lopez-Bayghen E, Ortega A. Glial glutamate transporters: new actors in brain signaling. IUBMB Life. (2011) 63:816-23. doi: 10.1002/iub.536

30. Bushong EA, Martone ME, Jones YZ, Ellisman MH. Protoplasmic astrocytes in CA1 stratum radiatum occupy separate anatomical domains. J Neurosci. (2002) 22:183-92. doi: 10.1523/jneurosci.22-01-00183.2002

31. Halassa MM, Fellin T, Haydon PG. The tripartite synapse: roles for gliotransmission in health and disease. Trends Mol Med. (2007) 13:5463. doi: 10.1016/j.molmed.2006.12.005

32. Allen NJ, Bennett ML, Foo LC, Wang GX, Chakraborty C, Stephen $\mathrm{J}$, et al. Astrocyte glypicans 4 and 6 promote formation of excitatory synapses via GluA1 AMPA receptors. Nature. (2012) 486:410-4. doi: 10.1038/nature11059

33. Wang AT, Lee SS, Sigman M, Dapretto M. Developmental changes in the neural basis of interpreting communicative intent. Soc Cogn Affect Neurosci. (2006) 1:107-21. doi: 10.1093/scan/nsl018

34. Charveriat M, Naus CC, Leybaert L, Saez JC, Giaume C. Connexindependent neuroglial networking as a new therapeutic target. Front Cell Neurosci. (2017) 11:174. doi: 10.3389/fncel.2017.00174

35. Giaume C. Astroglial wiring is adding complexity to neuroglial networking. Front Neuroenerget. (2010) 2:123. doi: 10.3389/fnene.2010.00129

36. Tanigami H, Okamoto T, Yasue Y, Shimaoka M. Astroglial integrins in the development and regulation of neurovascular units. Pain Res Treat. (2012) 2012:964652. doi: $10.1155 / 2012 / 964652$
37. Pekny M, Nilsson M. Astrocyte activation and reactive gliosis. Glia. (2005) 50:427-34. doi: 10.1002/glia.20207

38. Iliff JJ, Wang M, Liao Y, Plogg BA, Peng W, Gundersen GA, et al. A paravascular pathway facilitates CSF flow through the brain parenchyma and the clearance of interstitial solutes, including amyloid beta. Sci. Transl. Med. (2012) 4:147ra11. doi: 10.1126/scitranslmed.3003748

39. Plog BA, Nedergaard M. The glymphatic system in central nervous system health and disease: past, present, and future. Annu Rev Pathol. (2018) 13:379-94. doi: 10.1146/annurev-pathol-051217-111018

40. Verkhratsky A, Nedergaard M. The homeostatic astroglia emerges from evolutionary specialization of neural cells. Philos Trans Royal Soc London Ser B Biol Sci. (2016) 371:428. doi: 10.1098/rstb.2015.0428

41. Bechmann I, Galea I, Perry VH. What is the blood-brain barrier (not)? Trends Immunol. (2007) 28:5-11. doi: 10.1016/j.it.2006.11.007

42. Ransohoff RM, Brown MA. Innate immunity in the central nervous system. J Clin Invest. (2012) 122:1164-71. doi: 10.1172/jci58644

43. Farina C, Aloisi F, Meinl E. Astrocytes are active players in cerebral innate immunity. Trends Immunol. (2007) 28:138-45. doi: 10.1016/j.it.2007.01.005

44. Klein RS, Hunter CA. Protective and pathological immunity during central nervous system infections. Immunity. (2017) 46:891-909. doi: 10.1016/j.immuni.2017.06.012

45. Lyck L, Santamaria ID, Pakkenberg B, Chemnitz J, Schroder HD, Finsen B, et al. An empirical analysis of the precision of estimating the numbers of neurons and glia in human neocortex using a fractionator-design with sub-sampling. J Neurosci Methods. (2009) 182:143-56. doi: 10.1016/j.jneumeth.2009.06.003

46. Pelvig DP, Pakkenberg H, Stark AK, Pakkenberg B. Neocortical glial cell numbers in human brains. Neurobiol Aging. (2008) 29:175462. doi: 10.1016/j.neurobiolaging.2007.04.013

47. Alliot F, Godin I, Pessac B. Microglia derive from progenitors, originating from the yolk sac, and which proliferate in the brain. Brain Res Dev Brain Res. (1999) 117:145-52. doi: 10.1016/s0165-380600113-3

48. da Fonseca AC, Matias D, Garcia C, Amaral R, Geraldo LH, Freitas C, et al. The impact of microglial activation on blood-brain barrier in brain diseases. Front Cell Neurosci. (2014) 8:362. doi: 10.3389/fncel.2014.00362

49. Pont-Lezica L, Bechade C, Belarif-Cantaut Y, Pascual O, Bessis A. Physiological roles of microglia during development. J Neurochem. (2011) 119:901-8. doi: 10.1111/j.1471-4159.2011.07504.x

50. Nimmerjahn A, Kirchhoff F, Helmchen F. Resting microglial cells are highly dynamic surveillants of brain parenchyma in vivo. Science. (2005) 308:13148. doi: $10.1126 /$ science. 1110647

51. Schafer DP, Stevens B. Phagocytic glial cells: sculpting synaptic circuits in the developing nervous system. Curr Opin Neurobiol. (2013) 23:1034-40. doi: 10.1016/j.conb.2013.09.012

52. Block ML, Hong JS. Chronic microglial activation and progressive dopaminergic neurotoxicity. Biochem Soc Trans. (2007) 35:112732. doi: 10.1042/bst0351127

53. Farfara D, Lifshitz V, Frenkel D. Neuroprotective and neurotoxic properties of glial cells in the pathogenesis of Alzheimer's disease. J Cell Mol Med. (2008) 12:762-80. doi: 10.1111/j.1582-4934.2008.00314.x

54. Colombo E, Farina C. Astrocytes: key regulators of neuroinflammation. Trends Immunol. (2016) 37:608-20. doi: 10.1016/j.it.2016.06.006

55. Mracsko E, Veltkamp R. Neuroinflammation after intracerebral hemorrhage. Front Cell Neurosci. (2014) 8:388. doi: 10.3389/fncel.2014. 00388

56. Ohnishi M, Katsuki H, Fukutomi C, Takahashi M, Motomura M, Fukunaga $\mathrm{M}$, et al. HMGB1 inhibitor glycyrrhizin attenuates intracerebral hemorrhage-induced injury in rats. Neuropharmacology. (2011) 61:97580. doi: 10.1016/j.neuropharm.2011.06.026

57. Dudvarski Stankovic N, Teodorczyk M, Ploen R, Zipp F, Schmidt MHH. Microglia-blood vessel interactions: a doubleedged sword in brain pathologies. Acta Neuropathol. (2016) 131:347-63. doi: 10.1007/s00401-015-1524-y

58. Block ML, Zecca L, Hong JS. Microglia-mediated neurotoxicity: uncovering the molecular mechanisms. Nat Rev Neurosci. (2007) 8:57-69. doi: 10.1038/nrn2038

59. Orihuela R, McPherson CA, Harry GJ. Microglial M1/M2 polarization and metabolic states. Br J Pharmacol. (2016) 173:649-65. doi: 10.1111/bph.13139 
60. Boche D, Perry VH, Nicoll JA. Review: activation patterns of microglia and their identification in the human brain. Neuropathol Appl Neurobiol. (2013) 39:3-18. doi: 10.1111/nan.12011

61. Pan J, Jin JL, Ge HM, Yin KL, Chen X, Han LJ, et al. Malibatol A regulates microglia $\mathrm{M} 1 / \mathrm{M} 2$ polarization in experimental stroke in a PPAR gamma-dependent manner. J Neuroinflammation. (2015) 12:51. doi: 10.1186/s12974-015-0270-3

62. Ajmone-Cat MA, Mancini M, De Simone R, Cilli P, Minghetti L. Microglial polarization and plasticity: evidence from organotypic hippocampal slice cultures. Glia. (2013) 61:1698-711. doi: 10.1002/glia.22550

63. Lampron A, Elali A, Rivest S. Innate immunity in the CNS: redefining the relationship between the CNS and Its environment. Neuron. (2013) 78:214-32. doi: 10.1016/j.neuron.2013.04.005

64. David S, Kroner A. Repertoire of microglial and macrophage responses after spinal cord injury. Nat Rev Neurosci. (2011) 12:388-99. doi: 10.1038/nr n3053

65. Ramaglia V, Baas F. Innate immunity in the nervous system. In: Verhaagen J, Hol EM, Huitenga I, Wijnholds J, Bergen AB, Boer GJ, et al., editors. Neurotherapy: Progress in Restorative Neuroscience and Neurology. Amsterdam: Elsevier Science Bv (2009). p. 95-123.

66. Anderson MA, Burda JE, Ren Y, Ao Y, O'Shea TM, Kawaguchi R, et al. Astrocyte scar formation aids central nervous system axon regeneration. Nature. (2016) 532:195-200. doi: 10.1038/nature17623

67. Sofroniew MV. Astrogliosis. Cold Spring Harb. Perspect. Biol. (2014) 7:a020420. doi: 10.1101/cshperspect.a020420

68. Gundersen GA, Vindedal GF, Skare O, Nagelhus EA. Evidence that pericytes regulate aquaporin-4 polarization in mouse cortical astrocytes. Brain Struct Funct. (2014) 219:2181-6. doi: 10.1007/s00429-013-0629-0

69. Lunde LK, Camassa LM, Hoddevik EH, Khan FH, Ottersen OP, Boldt HB, et al. Postnatal development of the molecular complex underlying astrocyte polarization. Brain Struct Function. (2015) 220:2087101. doi: 10.1007/s00429-014-0775-Z

70. Mathiisen TM, Lehre KP, Danbolt NC, Ottersen OP. The perivascular astroglial sheath provides a complete covering of the brain microvessels: an electron microscopic 3D reconstruction. Glia. (2010) 58:1094-103. doi: 10.1002/glia.20990

71. Paulson OB, Kanno I, Reivich M, Sokoloff L. History of international society for cerebral blood flow and metabolism. J Cerebral Blood Flow Metab. (2012) 32:1099-106. doi: 10.1038/jcbfm.2011.183

72. Magaki SD, Williams CK, Vinters HV. Glial function (and dysfunction) in the normal and ischemic brain. Neuropharmacology. (2018) 134:21825. doi: 10.1016/j.neuropharm.2017.11.009

73. Wang J, Dore S. Heme oxygenase-1 exacerbates early brain injury after intracerebral haemorrhage. Brain. (2007) 130:164352. doi: 10.1093/brain/awm095

74. Xue $M$, Del Bigio MR. Intracerebral injection of autologous whole blood in rats: time course of inflammation and cell death. Neurosci Lett. (2000) 283:230-2. doi: 10.1016/s0304-3940 00971-x

75. Wu H, Zhang Z, Hu X, Zhao R, Song $\mathrm{Y}$, Ban $\mathrm{X}$, et al. Dynamic changes of inflammatory markers in brain after hemorrhagic stroke in humans: a postmortem study. Brain Res. (2010) 1342:111-7. doi: 10.1016/j.brainres.2010.04.033

76. Zhang Z, Liu Y, Huang Q, Su Y, Zhang Y, Wang G, et al. NF-kappaB activation and cell death after intracerebral hemorrhage in patients. Neurol Sci. (2014) 35:1097-102. doi: 10.1007/s10072-014-1657-0

77. Liesz A, Middelhoff M, Zhou W, Karcher S, Illanes S, Veltkamp R. Comparison of humoral neuroinflammation and adhesion molecule expression in two models of experimental intracerebral hemorrhage. Exp Transl Stroke Med. (2011) 3:11. doi: 10.1186/2040-7378-3-11

78. Matsushita H, Hijioka M, Ishibashi H, Anan J, Kurauchi Y, Hisatsune A, et al. Suppression of CXCL2 upregulation underlies the therapeutic effect of the retinoid Am80 on intracerebral hemorrhage in mice. J Neurosci Res. (2014) 92:1024-34. doi: 10.1002/jnr.23379

79. Lin S, Yin Q, Zhong Q, Lv FL, Zhou Y, Li JQ, et al. Heme activates TLR4-mediated inflammatory injury via MyD88/TRIF signaling pathway in intracerebral hemorrhage. J Neuroinflammation. (2012) 9:46. doi: 10.1186/1742-2094-9-46
80. Wasserman JK, Zhu X, Schlichter LC. Evolution of the inflammatory response in the brain following intracerebral hemorrhage and effects of delayed minocycline treatment. Brain Res. (2007) 1180:140-54. doi: 10.1016/j.brainres.2007.08.058

81. Xie RX, Li DW, Liu XC, Yang MF, Fang J, Sun BL, et al. Carnosine attenuates brain oxidative stress and apoptosis after intracerebral hemorrhage in rats. Neurochem Res. (2017) 42:541-51. doi: 10.1007/s11064-016-2104-9

82. Clausen BH, Lambertsen KL, Babcock AA, Holm TH, Dagnaes-Hansen F, Finsen B. Interleukin-1beta and tumor necrosis factor-alpha are expressed by different subsets of microglia and macrophages after ischemic stroke in mice. J Neuroinflammation. (2008) 5:46. doi: 10.1186/1742-2094-5-46

83. Clausen BH, Lambertsen KL, Dagnaes-Hansen F, Babcock AA, von Linstow CU, Meldgaard M, et al. Cell therapy centered on IL-1Ra is neuroprotective in experimental stroke. Acta Neuropathol. (2016) 131:77591. doi: 10.1007/s00401-016-1541-5

84. Michelucci A, Heurtaux T, Grandbarbe L, Morga E, Heuschling P. Characterization of the microglial phenotype under specific pro-inflammatory and anti-inflammatory conditions: effects of oligomeric and fibrillar amyloid-beta. J Neuroimmunol. (2009) 210:3-12. doi: 10.1016/j.jneuroim.2009.02.003

85. Lambertsen KL, Clausen BH, Babcock AA, Gregersen R, Fenger $\mathrm{C}$, Nielsen $\mathrm{HH}$, et al. Microglia protect neurons against ischemia by synthesis of tumor necrosis factor. J Neurosci. (2009) 29:1319-30. doi: 10.1523/jneurosci.5505-08.2009

86. Wang JM, Jiang $\mathrm{C}$, Zhang $\mathrm{K}$, Lan $\mathrm{X}$, Chen XM, Zang WD, et al. Melatonin receptor activation provides cerebral protection after traumatic brain injury by mitigating oxidative stress and inflammation via the Nrf2 signaling pathway. Free Radic Biol Med. (2019) 131:345-55. doi: 10.1016/j.freeradbiomed.2018. 12.014

87. Chen SH, Oyarzabal EA, Sung YF, Chu CH, Wang Q, Chen SL, et al. Microglial regulation of immunological and neuroprotective functions of astroglia. Glia. (2015) 63:118-31. doi: 10.1002/glia.22738

88. Lambertsen KL, Meldgaard M, Ladeby R, Finsen B. A quantitative study of microglial-macrophage synthesis of tumor necrosis factor during acute and late focal cerebral ischemia in mice. J Cereb Blood Flow Metab. (2005) 25:119-35. doi: 10.1038/sj.jcbfm.9600014

89. Mayne M, Fotheringham J, Yan HJ, Power C, Del Bigio MR, Peeling J, et al. Adenosine A2A receptor activation reduces proinflammatory events and decreases cell death following intracerebral hemorrhage. Ann Neurol. (2001) 49:727-35. doi: 10.1002/ana.1010

90. Luheshi NM, Rothwell NJ, Brough D. Dual functionality of interleukin1 family cytokines: implications for anti-interleukin-1 therapy. $\mathrm{Br}$ J Pharmacol. (2009) 157:1318-29. doi: 10.1111/j.1476-5381.2009. 00331.x

91. Vezzani A, Conti M, De Luigi A, Ravizza T, Moneta D, Marchesi F, et al. Interleukin-1beta immunoreactivity and microglia are enhanced in the rat hippocampus by focal kainate application: functional evidence for enhancement of electrographic seizures. J Neurosci. (1999) 19:5054-65.

92. Wagner KR, Beiler S, Beiler C, Kirkman J, Casey K, Robinson T, et al. Delayed profound local brain hypothermia markedly reduces interleukinlbeta gene expression and vasogenic edema development in a porcine model of intracerebral hemorrhage. Acta Neurochir Suppl. (2006) 96:177-82. doi: 10.1007/3-211-30714-1_39

93. Xi G, Hua Y, Keep RF, Younger JG, Hoff JT. Systemic complement depletion diminishes perihematomal brain edema in rats. Stroke. (2001) 32:1627. doi: 10.1161/01.Str.32.1.162

94. Aronowski J, Hall CE. New horizons for primary intracerebral hemorrhage treatment: experience from preclinical studies. Neurol Res. (2005) 27:268-79. doi: 10.1179/016164105x 25225

95. Ekdahl CT, Kokaia Z, Lindvall O. Brain inflammation and adult neurogenesis: the dual role of microglia. Neuroscience. (2009) 158:10219. doi: 10.1016/j.neuroscience.2008.06.052

96. Sansing LH, Harris TH, Welsh FA, Kasner SE, Hunter CA, Kariko K. Toll-like receptor 4 contributes to poor outcome after intracerebral hemorrhage. Ann Neurol. (2011) 70:646-56. doi: 10.1002/ana. 22528 
97. Holm TH, Draeby D, Owens T. Microglia are required for astroglial tolllike receptor 4 response and for optimal TLR2 and TLR3 response. (2012) 60:630-8. doi: 10.1002/glia.22296

98. Tarassishin L, Suh HS, Lee SC. LPS and IL-1 differentially activate mouse and human astrocytes: role of CD14. Glia. (2014) 62:9991013. doi: 10.1002/glia.22657

99. Teh DBL, Prasad A, Jiang W, Ariffin MZ, Khanna S, Belorkar A, et al. Transcriptome analysis reveals neuroprotective aspects of human reactive astrocytes induced by Interleukin 1 beta. Sci Rep-Uk. (2017) 7. doi: 10.1038/s41598-017-13174-w

100. Yang C-M, Hsieh H-L, Yu P-H, Lin C-C, Liu S-W. IL-1 beta induces MMP-9-dependent brain astrocytic migration via transactivation of PDGF receptor/NADPH oxidase 2-derived reactive oxygen species signals. $\mathrm{Mol}$ Neurobiol. (2015) 52:303-17. doi: 10.1007/s12035-014-8838-y

101. Buffo A, Rolando C, Ceruti S. Astrocytes in the damaged brain: molecular and cellular insights into their reactive response and healing potential. Biochem Pharmacol. (2010) 79:77-89. doi: 10.1016/j.bcp.2009.09.014

102. Gao T-L, Yuan X-T, Yang D, Dai H-L, Wang W-J, Peng X, et al. Expression of HMGB1 and RAGE in rat and human brains after traumatic brain injury. J Trauma Acute Care Surgery. (2012) 72:6439. doi: 10.1097/TA.0b013e31823c54a6

103. Hayakawa K, Qiu J, Lo EH. Biphasic actions of HMGB1 signaling in inflammation and recovery after stroke. Ann N Y Acad Sci. (2010) 1207:50-7. doi: 10.1111/j.1749-6632.2010.05728.x

104. Kim J-B, Sig Choi J, Yu Y-M, Nam K, Piao C-S, Kim S-W, et al. HMGB1, a novel cytokine-like mediator linking acute neuronal death and delayed neuroinflammation in the postischemic brain. J Neurosci. (2006) 26:641321. doi: 10.1523/jneurosci.3815-05.2006

105. Murakami K, Koide M, Dumont TM, Russell SR, Tranmer BI, Wellman GC. Subarachnoid hemorrhage induces gliosis and increased expression of the pro-inflammatory cytokine high mobility group box 1 protein. Transl Stroke Res. (2011) 2:72-9. doi: 10.1007/s12975-010-0052-2

106. Lei C, Lin S, Zhang C, Tao W, Dong W, Hao Z, et al. Highmobility group boxl protein promotes neuroinflammation after intracerebral hemorrhage in rats. Neuroscience. (2013) 228:190-9. doi: 10.1016/j.neuroscience.2012.10.023

107. Wu H, Wu T, Han X, Wan J, Jiang C, Chen W, et al. Cerebroprotection by the neuronal PGE(2) receptor EP2 after intracerebral hemorrhage in middle-aged mice. J Cerebral Blood Flow Metab. (2017) 37:3951. doi: 10.1177/0271678x15625351

108. Zhao X, Wu T, Chang C-F, Wu H, Han X, Li Q, et al. Toxic role of prostaglandin E-2 receptor EP1 after intracerebral hemorrhage in mice. Brain Behav Immunity. (2015) 46:293-310. doi: 10.1016/j.bbi.2015.02.011

109. Wang R, Zhang Q, Yang S, Guo Q. TNF-alpha induces the release of high mobility group protein $\mathrm{B} 1$ through $\mathrm{p} 38$ mitogen-activated protein kinase pathway in microglia. Zhong nan da xue xue bao Yi xue ban. (2015) 40:96772. doi: 10.11817/j.issn.1672-7347.2015.09.004

110. Yang Q-W, Lu F-L, Zhou Y, Wang L, Zhong Q, Lin S, et al. HMBG1 mediates ischemia-reperfusion injury by TRIF-adaptor independent Tolllike receptor 4 signaling. J Cerebral Blood Flow Metab. (2011) 31:593605. doi: $10.1038 /$ jcbfm.2010.129

111. Peng J, Zhou F, Wang Y, Xu Y, Zhang H, Zou F, et al. Differential response to lead toxicity in rat primary microglia and astrocytes. Toxicol Appl Pharmacol. (2019) 363:64-71. doi: 10.1016/j.taap.2018. 11.010

112. Davalos D, Grutzendler J, Yang G, Kim JV, Zuo Y, Jung S, et al. ATP mediates rapid microglial response to local brain injury in vivo. Nat Neurosci. (2005) 8:752-8. doi: 10.1038/nn1472

113. Shinozaki Y, Shibata K, Yoshida K, Shigetomi E, Gachet C, Ikenaka K, et al. Transformation of astrocytes to a neuroprotective phenotype by microglia via P2Y(1) receptor downregulation. Cell Rep. (2017) 19:115164. doi: 10.1016/j.celrep.2017.04.047

114. Norden DM, Fenn AM, Dugan A, Godbout JP. TGF beta produced by IL-10 redirected astrocytes attenuates microglial activation. Glia. (2014) 62:881-95. doi: 10.1002/glia.22647

115. Burda JE, Sofroniew MV. Reactive gliosis and the multicellular response to CNS damage and disease. Neuron. (2014) 81:22948. doi: 10.1016/j.neuron.2013.12.034
116. D’Orleans-Juste P, Ndunge OBA, Desbiens L, Tanowitz HB, Desruisseaux MS. Endothelins in inflammatory neurological diseases. Pharmacol Ther. (2019) 194:145-60. doi: 10.1016/j.pharmthera.2018.10.001

117. Stephan AH, Barres BA, Stevens B. The complement system: an unexpected role in synaptic pruning during development and disease. In: Hyman SE, editor. Annual Review of Neuroscience. (2012). p. 369-89.

118. Lian H, Litvinchuk A, Chiang ACA, Aithmitti N, Jankowsky JL, Zheng H. Astrocyte-microglia cross talk through complement activation modulates amyloid pathology in mouse models of Alzheimer's disease. J Neurosci. (2016) 36:577-89. doi: 10.1523/jneurosci.2117-15.2016

119. Lian H, Yang L, Cole A, Sun L, Chiang ACA, Fowler SW, et al. NF kappa B-activated astroglial release of complement C3 compromises neuronal morphology and function associated with Alzheimer's disease. Neuron. (2015) 85:101-15. doi: 10.1016/j.neuron.2014.11.018

120. Allaman I, Belanger M, Magistretti PJ. Astrocyte-neuron metabolic relationships: for better and for worse. Trends Neurosci. (2011) 34:7687. doi: 10.1016/j.tins.2010.12.001

121. Rosell A, Vilalta A, Garcia-Berrocoso T, Fernandez-Cadenas I, DominguesMontanari S, Cuadrado E, et al. Brain perihematoma genomic profile following spontaneous human intracerebral hemorrhage. PLoS ONE. (2011) 6:16750. doi: 10.1371/journal.pone.0016750

122. McKimmie CS, Graham GJ. Astrocytes modulate the chemokine network in a pathogen-specific manner. Biochem Biophys Res Commun. (2010) 394:1006-11. doi: 10.1016/j.bbrc.2010.03.111

123. Luo X, Tai WL, Sun L, Pan Z, Xia Z, Chung SK, et al. Crosstalk between astrocytic CXCL12 and microglial CXCR4 contributes to the development of neuropathic pain. Mol Pain. (2016) 12. doi: 10.1177/1744806916636385

124. Xu JW, Dong HQ, Qian QQ, Zhang X, Wang YW, Jin WJ, et al. Astrocytederived CCL2 participates in surgery-induced cognitive dysfunction and neuroinflammation via evoking microglia activation. Behav Brain Res. (2017) 332:145-53. doi: 10.1016/j.bbr.2017.05.066

125. Liu GJ, Nagarajah R, Banati RB, Bennett MR. Glutamate induces directed chemotaxis of microglia. Eur J Neurosci. (2009) 29:110818. doi: 10.1111/j.1460-9568.2009.06659.x

126. Carpentier PA, Palmer TD. Immune influence on adult neural stem cell regulation and function. Neuron. (2009) 64:79-92. doi: 10.1016/j.neuron.2009.08.038

127. Lambertsen KL, Biber K, Finsen B. Inflammatory cytokines in experimental and human stroke. J Cereb Blood Flow Metab. (2012) 32:1677-98. doi: 10.1038/jcbfm.2012.88

128. Bernstein JE, Savla P, Dong F, Zampella B, Wiginton JGT, Miulli DE, et al. Inflammatory markers and severity of intracerebral hemorrhage. Cureus. (2018) 10:e3529. doi: 10.7759/cureus.3529

129. Fernandez-Lopez D, Faustino J, Klibanov AL, Derugin N, Blanchard E, Simon F, et al. Microglial cells prevent hemorrhage in neonatal focal arterial stroke. J Neurosci. (2016) 36:2881-93. doi: 10.1523/jneurosci.014015.2016

130. Wang G, Wang L, Sun Xg, Tang J. Haematoma scavenging in intracerebral haemorrhage: from mechanisms to the clinic. J Cell Mol Med. (2018) 22:76877. doi: $10.1111 /$ jcmm.13441

131. Wang G, Guo Z, Tong L, Xue F, Krafft PR, Budbazar E, et al. TLR7 (Toll-Like Receptor 7) facilitates heme scavenging through the BTK (Bruton Tyrosine Kinase)-CRT (Calreticulin)-LRP1 (Low-Density Lipoprotein ReceptorRelated Protein-1)-Hx (Hemopexin) pathway in murine intracerebral hemorrhage. Stroke. (2018) 49:3020-9. doi: 10.1161/strokeaha.118.022155

132. Chen $\mathrm{Z}$, Zhong $\mathrm{D}$, Li G, The role of microglia in viral encephalitis: a review. J Neuroinflammation. (2019). 16:76. doi: 10.1186/s12974-0191443-2

133. Maragakis NJ, Rothstein JD. Mechanisms of disease: astrocytes in neurodegenerative disease. Nat Clin Practice Neurol. (2006) 2:67989. doi: 10.1038/ncpneuro0355

134. Iadecola C. The neurovascular unit coming of age: a journey through neurovascular coupling in health and disease. Neuron. (2017) 96:1742. doi: 10.1016/j.neuron.2017.07.030

135. Pannell M, Meier MA, Szulzewsky F, Matyash V, Endres M, Kronenberg $\mathrm{G}$, et al. The subpopulation of microglia expressing functional muscarinic acetylcholine receptors expands in stroke and Alzheimer's disease. Brain Struct Funct. (2016) 221:1157-72. doi: 10.1007/s00429-014-0962-y 
136. Jha MK, Kim JH, Song GJ, Lee WH, Lee IK, Lee HW, et al. Functional dissection of astrocyte-secreted proteins: implications in brain health and diseases. Prog Neurobiol. (2018) 162:3769. doi: 10.1016/j.pneurobio.2017.12.003

137. Frei K, Bodmer S, Schwerdel C, Fontana A. Astrocyte-derived interleukin 3 as a growth factor for microglia cells and peritoneal macrophages. J Immunol. (1986) 137:3521-7.

138. Nichols MR, St-Pierre MK, Wendeln AC, Makoni NJ, Gouwens LK, Garrad EC, et al. Inflammatory mechanisms in neurodegeneration. J Neurochem. (2019) 149:562-81. doi: 10.1111/jnc.14674

139. Wolters FJ, Ikram MA. Epidemiology of dementia: the burden on society, the challenges for research. Method Mol Biol. (2018) 1750:314. doi: 10.1007/978-1-4939-7704-8_1

140. Michinaga S, Seno N, Fuka M, Yamamoto Y, Minami S, Kimura A, et al. Improvement of cold injury-induced mouse brain edema by endothelin ETB antagonists is accompanied by decreases in matrixmetalloproteinase 9 and vascular endothelial growth factor-A. Eur J Neurosci. (2015) 42:235670. doi: 10.1111/ejn.13020

141. Wu Y, Dissing-Olesen L, MacVicar BA, Stevens B. Microglia: dynamic mediators of synapse development and plasticity. Trends Immunol. (2015) 36:605-13. doi: 10.1016/j.it.2015.08.008

142. Bell-Temin H, Culver-Cochran AE, Chaput D, Carlson CM, Kuehl M, Burkhardt BR, et al. Novel molecular insights into classical and alternative activation states of microglia as revealed by stable isotope labeling by amino acids in cell culture (SILAC)-based proteomics. Mol Cell Proteomics. (2015) 14:3173-84. doi: 10.1074/mcp.M115.053926

143. Becerra-Calixto A, Cardona-Gómez GP. The role of astrocytes in neuroprotection after brain stroke: potential in cell therapy. Front Mol Neurosci. (2017) 10:88. doi: 10.3389/fnmol.2017. 00088
144. Krasemann S, Madore C, Cialic R, Baufeld C, Calcagno N, El Fatimy R, et al. The TREM2-APOE pathway drives the transcriptional phenotype of dysfunctional microglia in neurodegenerative diseases. Immunity. (2017) 47:566-81.e9. doi: 10.1016/j.immuni.2017.08.008

145. Polanco JC, Li C, Bodea LG, Martinez-Marmol R, Meunier FA, Gotz J. Amyloid-beta and tau complexity-towards improved biomarkers and targeted therapies. Nat Rev Neurol. (2018) 14:22-39. doi: 10.1038/nrneurol.2017.162

146. Nakanishi M, Niidome T, Matsuda S, Akaike A, Kihara T, Sugimoto H. Microglia-derived interleukin-6 and leukaemia inhibitory factor promote astrocytic differentiation of neural stem/progenitor cells. Eur J Neurosci. (2007) 25:649-58. doi: 10.1111/j.1460-9568.2007.05309.x

147. Christopherson KS, Ullian EM, Stokes CC, Mullowney CE, Hell JW, Agah A, et al. Thrombospondins are astrocyte-secreted proteins that promote CNS synaptogenesis. Cell. (2005) 120:421-33. doi: 10.1016/j.cell.2004.12.020

148. Harada K, Kamiya T, Tsuboi T. Gliotransmitter release from astrocytes: functional, developmental, and pathological implications in the brain. Front Neurosci. (2015) 9:499. doi: 10.3389/fnins.2015.00499

Conflict of Interest: The authors declare that the research was conducted in the absence of any commercial or financial relationships that could be construed as a potential conflict of interest.

Copyright (c) $2020 \mathrm{Liu}, \mathrm{Liu}, \mathrm{Bao}, \mathrm{Bai}$ and Wang. This is an open-access article distributed under the terms of the Creative Commons Attribution License (CC BY). The use, distribution or reproduction in other forums is permitted, provided the original author(s) and the copyright owner(s) are credited and that the original publication in this journal is cited, in accordance with accepted academic practice. No use, distribution or reproduction is permitted which does not comply with these terms. 